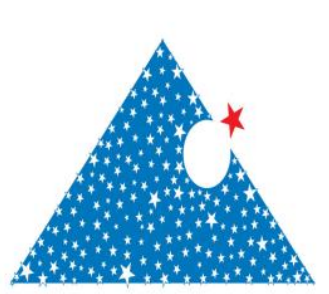

www.dergipark.gov.tr

ISSN:2148-3736

El-Cezerî Fen ve Mühendislik Dergisi

Cilt: 4, No: 3, 2017 (606-611)

El-Cezerî Journal of Science and

Engineering

Vol: 4, No: 3, 2017 (606-611)

\title{
ECJSE
}

Makale / Research Paper

\section{Farklı Gaz Basınçları Kullanılarak Soğuk Metal Transferi (CMT) ile Birleştirilmiş Alüminyum 6082-T6 Bağlantıların Mekanik Özelliklerinin İncelenmesi}

\author{
Uğur ÖZSARAÇ ${ }^{1, *}$, Salim ASLANLAR ${ }^{1}$, Faruk VAROL ${ }^{2}$, Şafak IŞIK ${ }^{1}$, Erman FERİK $^{1}$ \\ ${ }^{1}$ Sakarya Üniversitesi Teknoloji Fakültesi, Metalurji ve Malzeme Mühendisliği Bölümü, 54187 Sakarya/ \\ TÜRKIYE \\ ${ }^{2}$ Sakarya Üniversitesi, Karasu Meslek Yüksek Okulu, Sakarya/ TÜRKIYYE \\ ozsarac@sakarya.edu.tr, aslanlar@ sakarya.edu.tr, fvarol@sakarya.edu.tr, safkisk@ gmail.com, ermanferik@ gmail.com
}

\begin{abstract}
Özet: Bu çalışmada, 1,0 milimetre kalınlığa sahip Alüminyum 6082-T6 plakaları magnezyum esaslı (AlMg5) teliyle soğuk metal transferi yöntemiyle birleştirilmiştir. Numuneler, alın birleştirme formunda hazırlanmıştır. Koruyucu gaz olarak argon kullanılmışırı ve birleştirme işlemleri 20o çalışma açısıyla yapılmıştır. Soğuk metal transferi yöntemiyle farklı gaz basınçlarında kaynağı yapılan Alüminyum 6082 parçaların çekme dayanımı değerleri belirlenmiştir, sertlik değerleri ölçülmüş ve makro yapıları optik mikroskopta incelenmiştir.
\end{abstract}

Anahtar kelimeler: CMT, Alüminyum 6082, Çekme mukavemeti

\section{Investigation of Mechanical Properties of Aluminium 6082-T6 Alloys Joined by Cold Metal Transfer by Using Different Gas Pressure}

\begin{abstract}
In this study, Aluminium 6082-T6 plates having 1.0 milimeter thickness were joined by magnesiumbased (AlMg5) wire in cold metal transfer technique. Specimens were prepared in butt joint form. Argon was used as shielding gas and joining operations were done with 200 working angle. Joining operations were done with six different gas pressures of $9,10,11,12,13$ and 14 1/min. After that, tensile properties of joints were determined and macro-structures of joints were investigated in order to see the joinability of Aluminium 6082T6 alloy by Cold Metal Transfer (CMT) technique. Finally, the micro-hardness values of specimens were measured.
\end{abstract}

Keywords: Cold Metal Transfer, Aluminium 6082, Tensile strength

\section{Giriş}

Son yıllarda çeşitli endüstriyel alanlarda özellikle otomotiv, havacılık, uzay teknolojileri, denizcilik ve diğer sektörlerde arzu edilen amaca yönelik gereken daha özel karakterli malzemelerin istekleri artmıştır [1]. $\mathrm{Bu}$ malzemelerde aranan yüksek dayanım, şekillendirilebilme, süneklik, birleştirilebilirlik özel karakterli malzemelerin üretimini zorunlu kılmıştır [2]. Bunların dışında malzemelerde istenen hafiflik, yakıt verimliliği artırmak ve çevre koruma bilinci zorunluluk haline gelmiştir [3]. Bu gelişmeler geleneksel malzemelerin geliştirilmesine ya da yerini farklı malzemelerin kullanımına götürmüştür [4]. Bu malzemelerden biri olan alüminyum geleneksel bir metal olup aynı zamanda geliştirilmeye uygun bir metaldir. Hafiflik, geri dönüştürülebilirlik, 
yüksek mukavemet, süneklik, iyi birleştirilebilirlik ve korozyon direnci yanı sıra estetik görünümünden ötürü diğer malzemelerden daha çok ön plana çıkmaktadır [1,2].

Alüminyum ve alaşımları içerdikleri bileşim oranlarına göre farklı serilerde adlandırılmaktadır [5]. Sıkça kullanılan alüminyum serisi olan 6082-T6 serisi iyi kaynak edilebilirlik, iyi korozyon dayanımı, yüksek yorulma direnciyle tercih edilmektedir [3]. Alüminyum kaynağında çeşitli yöntemler kullanılmıştır. Alüminyum, üzerinde bulunan oksit tabakası, düşük ergime sıcaklığı, yüksek 1sıl iletiminden dolayı kaynağı diğer metallere kıyasla daha zor bir metaldir. Alüminyumun ergime sıcaklığ $650^{\circ} \mathrm{C}$ olmasına rağmen, $\mathrm{Al}_{2} \mathrm{O}_{3}$ oksit tabakasının ergime sicaklığ $2000^{\circ} \mathrm{C}^{\prime}$ lerin üstünde olan bir malzemedir. Bunun için yüksek 1sı girdisi olan kaynak yöntemleri tercih edilmektedir [6,7]. Fakat yüksek ısı girdisinden dolayı alüminyum malzemede tatmin edici sonuçlar alınamamıştır. İçyap1 değişikliği ve yaşlanmadan ötürü mekanik özelliklerin düşüşü gözlenmiştir. Buna ek olarak kaynak yapılan kesitler inceldikçe isı iletimi hızlanmış, malzemede delik, porozite ve sicak çatlama gibi hatalar oluşmuştur [7]. Hafif malzemenin orijinal gücünü koruma gerekliliği geleneksel kaynak yöntemleriyle iyi bir şekilde sağlanamamıştır [7]. Bu durum kaynak sonrası 1sıl işlem gerekliliklerini artırmış; zaman ve iş gücü kayıplarına yol açmış ve tasarım süreçlerini zorlamıştır. Son yıllarda kaynak makineleri ve ekipmanları üreten firmalar ince kesitli levhalarda bilhassa hafif, düşük yoğunluklu hassas metallerde yüksek 1s1 girdisinden kaynaklı olan mekanik özellik düşüşü, porozite, sıcak çatlama hataları üzerinde durmuş ve bunları gidermenin yollarını araştırmışlardır [5,8,9]. Bu araştırmalar sonucu Fronius firması tarafından geliştirilmiş olan CMT (Soğuk Metal Transferi) yöntemi bulunmuştur [10,11]. Bu yöntemle alüminyum gibi hafif malzemelerin ve dar kesitli malzemelerde karşılaşılan mekanik özelliklerde düşme, sıcak çatlama problemleri giderilmeye başlanmıştır. [1,12] CMT işleminde en önemli yenilik kaynak esnasında kaynak teli işlemidir $[13,14]$, tel kaynak esnasında kaynak nozulu içerisinde ileri ve geri çekme hareketi yaparak kısa devre oluşturur ve damlacık şeklinde ana metale geçmektedir $[14,15]$. Bu işleme bağlı olarak düşük 1sı girdisi ince malzemelerin kaynağında sağladığı kolaylık, düzgün kaynak yüzeyi, gözenek oluşumunda dikkate değer düşüş ve yüksek 1sı girişli kaynak yöntemlerindeki mekanik özelliklerine göre daha iyi mekanik özellikler elde edilmesiyle tercih edilmektedir.[13,14,15].

Yaptığımız bu çalışmada, otomotiv, havacılık, uzay teknolojileri, denizcilik sektörlerinde kullanılan 1mm kalınlıktaki Al 6082-T6 numuneler, alın birleştirme formunda, kaynak akım şiddeti ve kaynak süresi sabit tutularak farklı gaz basınçları altında soğuk metal transferi (CMT) yöntemi kullanılarak birleştirilmiştir. Bağlantıların mekanik özellikleri çekme testi ile tespit edilmiş, sertlik değerleri ölçülmüştür. Makro yapı görüntüleri elde edilmiş ve yorumlanmıştır.

\section{Materyal ve Metot}

Bu çalışmada, 200 × $200 \times 1 \mathrm{~mm}$ boyutlarında, alüminyum alaşımlarından Alüminyum 6082-T6 levha numuneler kullanılmıştır. Parçalar, \% $3 \mathrm{HNO}_{3}, \% 2 \mathrm{HCl}, \% 1 \mathrm{HF}$ ve \% $94 \mathrm{H}_{2} \mathrm{O}$ içeren Keller çözeltisiyle dağlanmıştır. Kullanılan levhaların ve telin analiz değerleri Tablo 1 ve Tablo 2'de verilmiştir.

Tablo 1. Deneylerde kullanılan Alüminyum 6082-T6 esas metalin kimyasal kompozisyonu

\begin{tabular}{lcccccccccc}
\hline Malzeme & $\mathbf{S i}$ & $\mathbf{F e}$ & $\mathbf{C u}$ & $\mathbf{M n}$ & $\mathbf{M g}$ & $\mathbf{C r}$ & $\mathbf{N i}$ & $\mathbf{Z n}$ & $\mathbf{T i}$ & Al \\
\hline Al 6082 & 0.88 & 0.43 & 0.08 & 0.47 & 0.71 & 0.03 & 0.01 & 0.04 & 0.03 & rest
\end{tabular}

Tablo 2. Deneylerde kullanılan 1,0 mm çaplı AlMg5 telin kimyasal kompoziyonu

\begin{tabular}{lccccc}
\hline Tel & Mg & Mn & $\mathbf{C r}$ & Ti & Al \\
\hline AlMg5 & 5.2 & 0.1 & 0.09 & 0.01 & Rest
\end{tabular}




\subsection{CMT işlemi}

Soğuk metal transferi işleminde Fronius A-4600 model CMT (Cold Metal Transfer) cihazı kullanılmıştır. Birleştirmeler alın alına şeklinde uygulanmıştır. Kaynak işleminde $1 \mathrm{~mm}$ kalınlığında magnezyum esaslı 1mm AlMg5 tel kullanılmıştır. Kaynak akım şiddeti 75 amper, kaynak süresi 25 saniye tutulmuştur, soğuk metal transferi ark torç açısı 200 olarak ayarlanmıştır, çalışmada saf Argon koruyucu gaz kullanılmıştır. Çalışma sırasında kaynak akım şiddeti, kaynak süresi, torç açısı sabit tutularak 9, 10, 11, 12, 13, 14 litre/dakika farklı gaz basınçlarında kaynak işlemi yapılmıştır.

\section{2. Çekme deneyleri}

Alüminyum 6082-T6 levhalar üzerinde EN895 standartlarında çekme deneyleri yapılmıştır. Çekme deneyinde kullanılan numunelerin çekme deneyi sonrası görünüşleri Şekil 1'de gösterilmiştir.

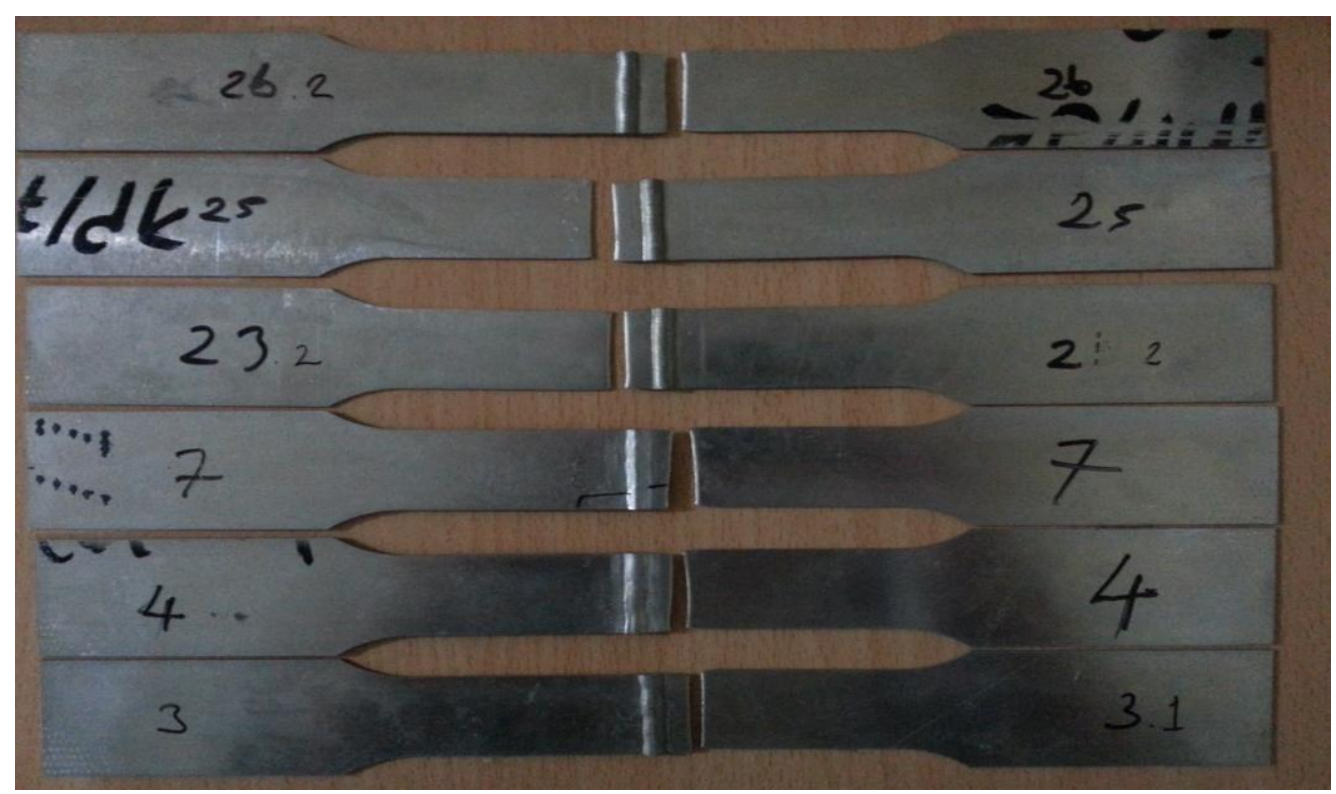

Şekil 1. Çekme deneyi sonrası parçaların görüntüleri

\section{Sonuçlar ve Tartışma}

\section{1. Çekme deneyi sonuçları}

Bu çalışmada EN895 standartlarında çekme numunesi hazırlanmıştır, "gaz basınçları" ve "çekme dayanımları" iki önemli parametre değerlendirmeye alınmıştır. İki parametre arasındaki ilişki Şekil 2'de verilmiştir.

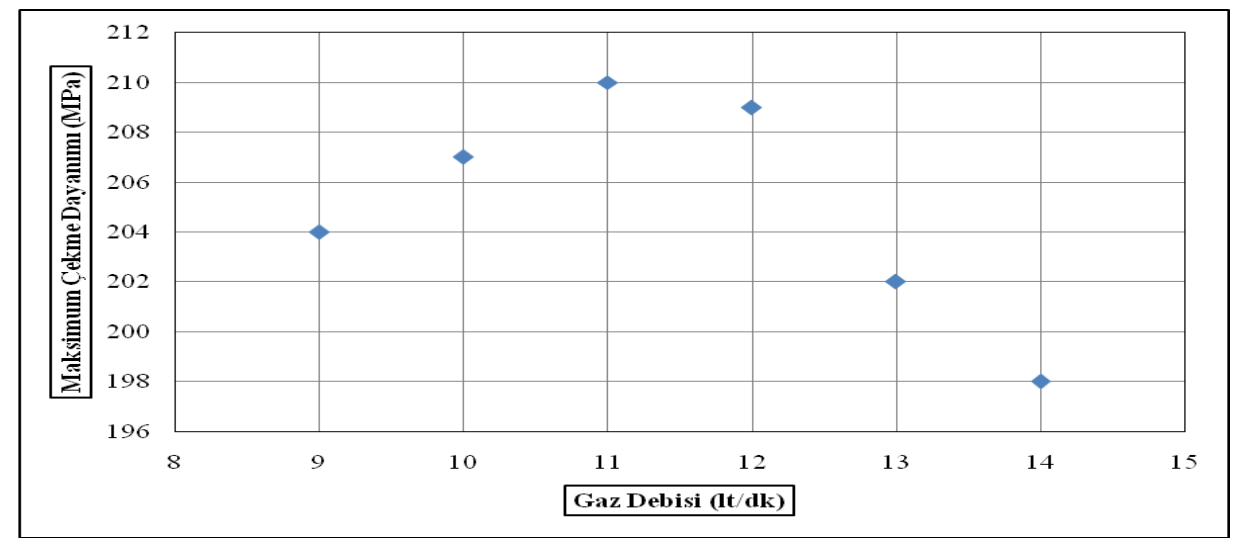

Şekil 2. Alın birleştirme formunda kaynak yapılan numunelerin çekme mukavemeti değerleri 
$\mathrm{Bu}$ grafikler incelendiğinde en yüksek çekme dayanımı olan $210 \mathrm{MPa}$ değerine 11 lt/dakika gaz debisinde ulaşıldığı görülmüştür. 12 lt/dakika üstünde debilere çıkıldığında, çekme dayanımında belirgin düşüşler gözlenmiştir.

\subsection{Makro-yapı değiş̧imleri}

Alüminyum 6082-T6 $1 \mathrm{~mm}$ kalınlığındaki levhalarla yapılan soğuk metal transferi işleminde makro yap1 incelemeleri yapılmış ve sonuçları incelenmiştir. Kaynak işleminde makro yapının gaz debisine bağlı olarak değiştiği gözlenmiştir (Şekil 3). Makro-yap1 görüntülerinin, Ryakala ve arkadaşının [7] ve Kumar ve arkadaşlarının [9] çalışmalarındaki yapılara benzediği görülmüştür.

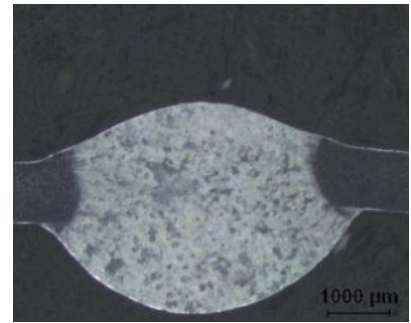

$9 \mathrm{l} / \mathbf{d} \mathbf{k}$

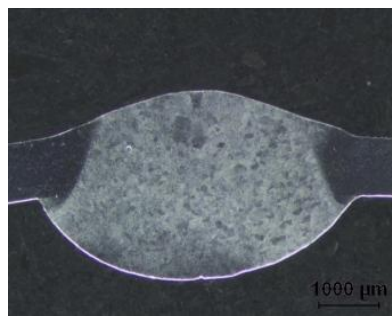

$12 \mathrm{l} / \mathrm{dk}$

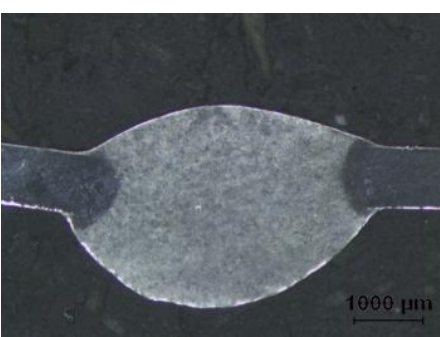

$10 \mathrm{l} / \mathrm{dk}$

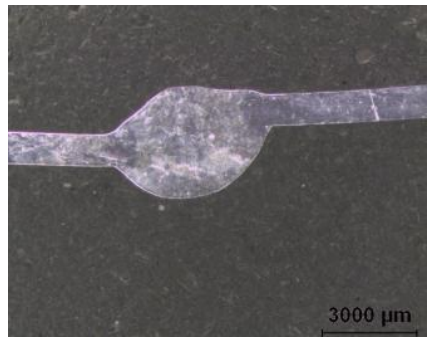

$13 \mathrm{l} / \mathbf{d k}$

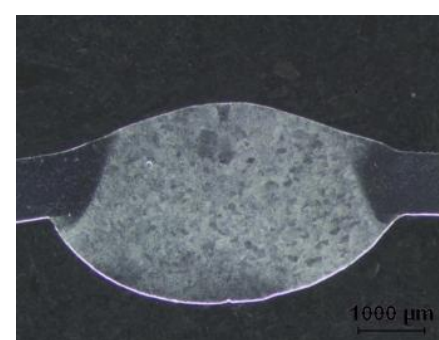

$11 \mathrm{l} / \mathrm{dk}$

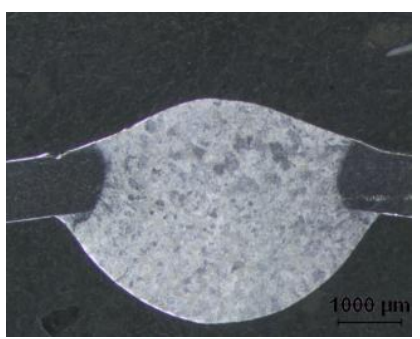

$14 \mathrm{l} / \mathrm{dk}$

Şekil 3. Kaynak bölgesinde çekilen makro-yapı resimleri

\subsection{Mikrosertlik}

Sertlik ölçümleri, Vickers sertlik ölçüm test metodu kullanılarak yapılmıştır, 100 gr yük ve piramit batıcı uç kullanılmıştır. Sertlik değerleri ana malzemeden kaynak bölgesi yönüne alınmıştır. Sertlik Kaynak metali, ITAB ve ana metal bölgelerinden alınan sertlik değerleri ve şekil 4'te gösterilen bölgelerden alınan sertlik değerleri şekil 5'te diyagram halinde verilmiştir.

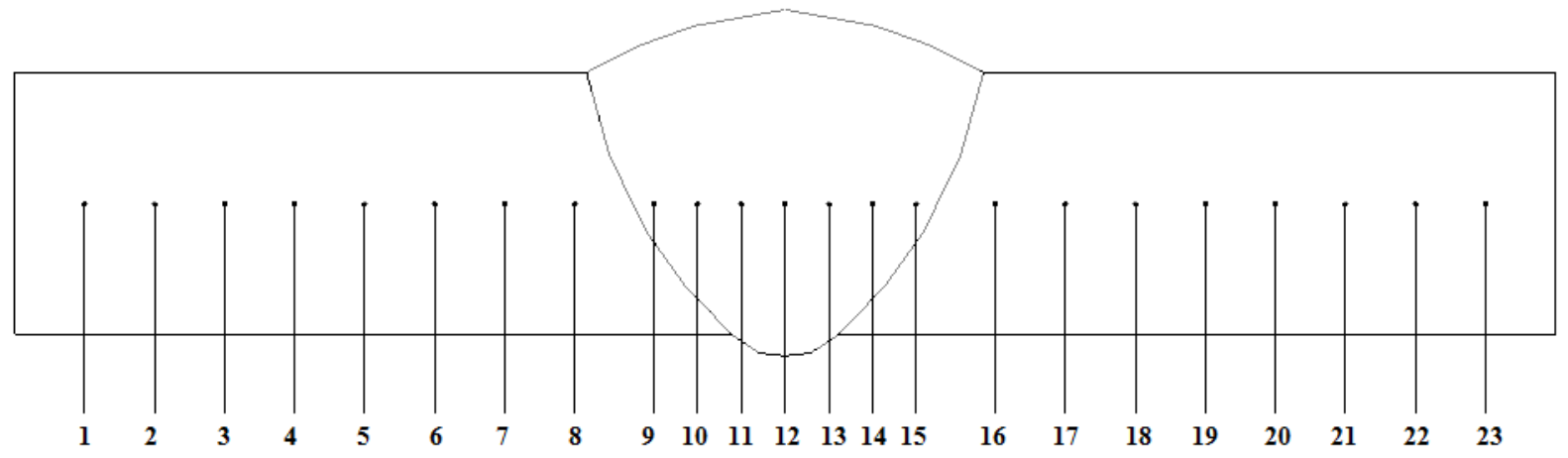

Şekil 4. Sertlik değerleri alınan noktalar 


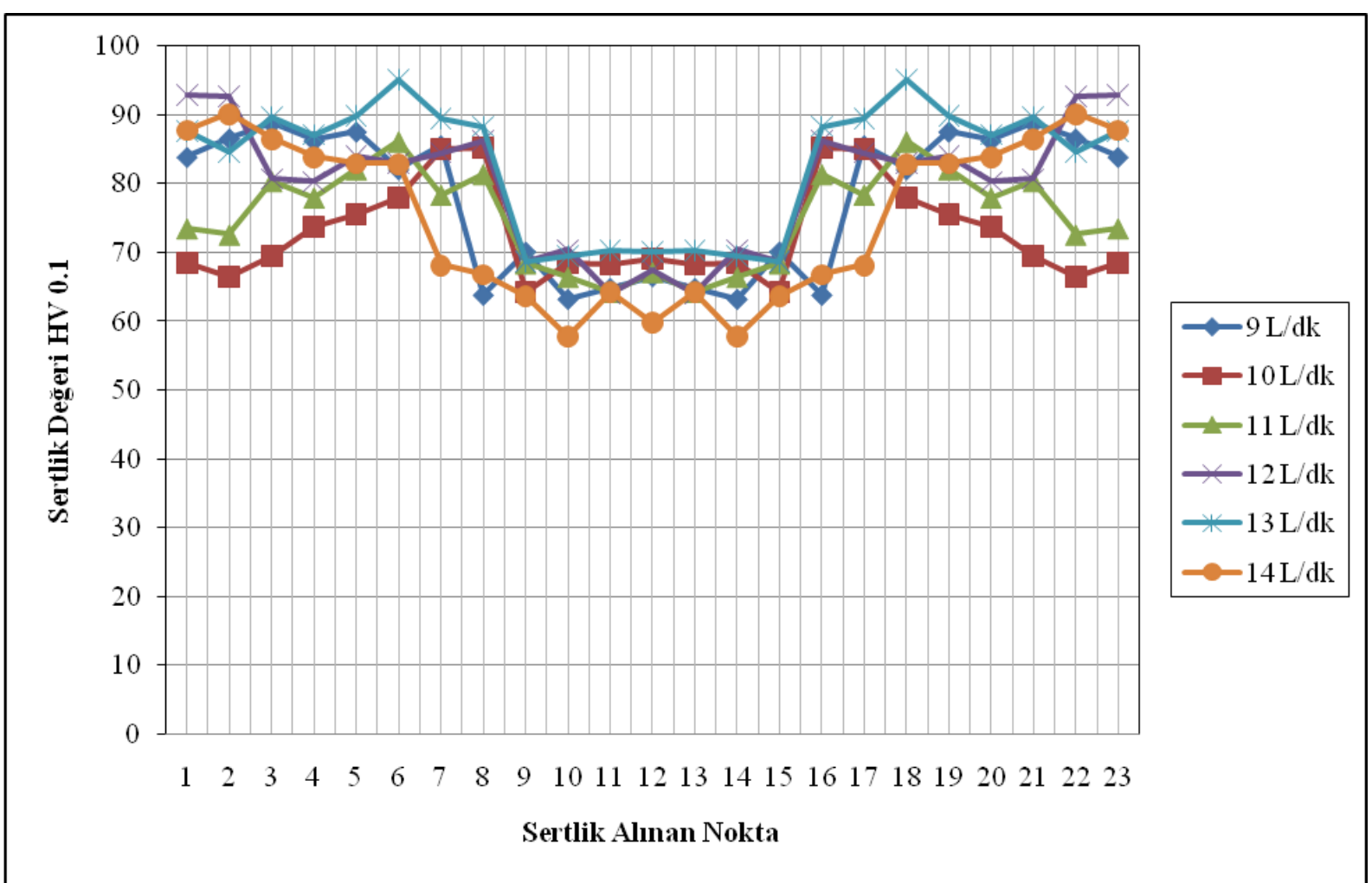

Şekil 5. Alın birleştirme sertlik değerleri ana metalden kaynak bölgesine doğru alınmıştır.

Sertlik değerinin, ana metalden kaynak bölgesine doğru gidildikçe düştüğü görülmektedir. Genel olarak ITAB bölgelerinde sertlik değerleri kaynak metalinin sertlik değerlerine göre yüksektir ama bazı parçalarda ITAB bölgesinin sertlik değerinin kaynak metali sertlik değeriyle aynı olduğu ya da kaynak metalinin sertlik değerinin ITAB sertlik değerinden yüksek çıktığ 1 gözlenmiştir. Sertlik değerleri 64 - 95 HV arasında değişmektedir. Gaz debisinin değişimi sertlik değerleri üstünde etkisi olduğu düşünülebilir. Sertlik değerlerindeki değişimlerin Ehab ve arkadaşının [16] ve Scialpi ve arkadaşlarının [17] çalışmalarındaki değerlere yakın çıktığı görülmüştür.

\section{Genel Sonuçlar}

Soğuk metal transferi yöntemiyle Alüminyum 6082-T6 levhaların, AlMg5 teliyle alın alına birleştirilebilirliği araştırılmıştır. Düşük 1sı girdisi nedeniyle, ana metalde az miktarda erime görülmüştür. Farklı gaz debilerinde, çekme mukavemeti, sertlik ve makro yapı incelemesi yapılmıştır. Çekme mukavemetlerinde gaz debisi arttıkça çekme mukavemetinin yükseldiği belirli bir litreden sonra düştüğü gözlenmiştir. Gaz debisiyle makro yapıda değişiklikler görülmüştür. Sertlik değerlerinin, gaz debisi arttıkça bazı parçalarda ana metalden kaynak bölgesine doğru düştüğü görülmüş̧ür.

\section{Teşekkür}

$\mathrm{Bu}$ çalışmada yardımlarından dolayı Fronius, Ermetal ve Oerlikon şirketlerine ve Seykoç Alüminyum'a teșekkür ederiz. 


\section{Kaynaklar}

[1] Yang, S., Zhang, J., Lian, J., Lei, Y., Welding of aluminum alloy to zinc coated steel by cold metal transfer, Material and Design, 49 (2013) 602-612.

[2] Moreira, P.M.G.P., Jesus, A.M.P., Ribeiro, A.S., Castro, P.M.S.T., Fatigue crack growth in friction stir welds of 6082-T6 and 6061-T6 aluminium alloys: A comparison, Theoretical and Applied Fracture Mechanic, 50 (2008) 81-91.

[3] Feng, J., Zhang, H., He, P., The CMT short-circuiting metal transfer process and its use in thin aluminium sheets welding, Materials and Design, 30 (2009) 1850-1852.

[4] Ahmad, R., Bakar, M.A., Effect of a post-weld heat treatment on the mechanical and microstructure properties of AA6061 joints welded by the gas metal arc welding cold metal transfer method, Materials and Design, 32 (2011) 5120-5126.

[5] Shang, J., Wang, K., Zhou, Q., Zhang, D., Huang, J., Li, G., Microstructure characteristics and mechanical properties of cold metal transfer welding, $\mathrm{Mg} / \mathrm{Al}$ dissimilar metals, Materials and Design, 34 (2012) 559-565.

[6] Cao, R., Wen, B.F., Chen, J.H., Wang, P.C., Cold metal transfer joining of magnesium AZ31Bto-aluminum A6061-T6, Materials Science and Engineering A, 560 (2013) 256-266.

[7] Rykala, J., Pfeifer, T., Robotised CMT welding of 6xxx series aluminium alloys, Biuletyn Instytutu Spawalnictwa, No. 6, (2013).

[8] Gungor, B., Kaluc, E., Taban, E., Şık, A., Mechanical and microstructural properties of robotic cold metal transfer (CMT) welded 5083-H111 and 6082-T651 aluminum alloys, Materials and Design, 54 (2014) 207-211.

[9] Kumar, R., Dilthey, U., Dwivedi, D.K., Ghosh, P.K., Thin sheet welding of Al 6082 alloy by AC pulse-GMA and AC wave pulse-GMA welding, Materials and Design, 30 (2009) 306313.

[10] Lorenzin, G., Rutili, G., The innovative use of low heat input in welding: experiences on 'cladding' and brazing using the CMT proces, Welding International, 23:8, (2009) 622-632.

[11] Zhang, H.T., Feng, J.C., He, P., Zhang, B.B., Chen, J.M., Wang, L., The arc characteristics and metal transfer behaviour of cold metal transfer and its use in joining aluminium to zinccoated steel, Materials Science and Engineering A, 499 (2009) 111-113.

[12] Meco, S., Pardal, G., Eder, A., Quintino, L., Software development for prediction of the weld bead in CMT and pulsed-MAG processes, Int J Adv Manuf Technol, 64 (2013) 171-178.

[13] Zhang, H.T., Feng, J.C., He, P., Hackl, H., Interfacial microstructure and mechanical properties of aluminium-zinc-coated steel joints made by a modified metal inert gas weldingbrazing process, Materials Characterization, 58 (2007) 588-592.

[14] Cao, R., Huand, Q., Chen, J.H., Wang, P.C., Cold metal transfer spor plug welding of AA6061-T6-to-galvanized steel for automotive applications, Journal of Alloys and Compounds, 585 (2014) 622-632.

[15] Pickin, C.G., Williams, S.W., Lunt, M., Characrterisation of the cold metal transfer (CMT) process and its application for low dilution cladding, Journal of Materials Processing Technology, 211 (2011) 496-502.

[16] Ehab, A., Danaf, E., El-Rayes, M.M., Microstructure and mechanical properties of friction stir welded 6082 AA in as welded and post weld heat treated conditions, Materials and Design, 46 (2013) 561-572.

[17] Scialpi, A., De Filippis, L.A.C., Cavaliere, P., Influence of shoulder geometry on microstructure and mechanical properties of friction stir welded 6082 aluminium alloy, Materials and Design, 28 (2007) 1124-1129. 